\title{
UMA ANÁLISE DA INTERDISCIPLINARIDADE NA DOCÊNCIA UNIVERSITÁRIA: A PERCEPÇÃO DOS PROFESSORES DA UESB
}

\section{INTERDISCIPLINARITY ON UNIVERSITY TEACHING: UESB TEACHERS PERCEPTION \\ UMA ANÁLISIS DE LA INTERDISCIPLINARIDAD EN LA DOCENCIA UNIVERSITÁRIA: UNA PERCEPCIÓN DOS PROFESORES DA UESB}

\author{
Andrêssa Rodrigues Silva \\ E-mail: contatorodrigues@live.com \\ Ennia Débora Passos Braga Pires \\ E-mail: enniadebora@yahoo.com.br \\ Universidade Estadual do Sudoeste da Bahia - UESB
}

\begin{abstract}
RESUMO
$O$ artigo apresenta os resultados de uma pesquisa teve como objetivo analisar a perspectiva docente sobre a contribuição da interdisciplinaridade na prática docente e na construção do conhecimento. Procurou-se averiguar o que pensam os docentes, sobre a interdisciplinaridade como fomentadora do desenvolvimento e competência docente tanto no campo do ensino quanto no campo da pesquisa; identificar a concepção dos docentes sobre a abordagem do conhecimento cientifico, a contextualização entre as ideias estudadas com a realidade dos discentes e a interação entre educador e educando, teoria e ação. O estudo fundamentou-se em autores contemporâneos, dentre os quais: Anastasiou (2006), Fazenda (2001; 2011), Masetto (2008), Pimenta (2000; 2008), Severino (2008) e Veiga (2006) que discutem a docência universitária. Foram entrevistados 10 (dez) professores dos cursos de Biologia, Química e Pedagogia de uma Instituição de Ensino Superior do Sudoeste da Bahia. Constatou-se que os docentes das distintas áreas do conhecimento percebem a interdisciplinaridade como uma abordagem que proporciona um ensino mais próximo da complexidade dos fatos sociais vivenciados pelos alunos, e que promove a dialogicidade entre os pares. Contudo, a pesquisa evidencia que, apesar dos docentes reconhecerem esses aspectos, a interdisciplinaridade é pouco pensada e exercida na instituição estudada. Os resultados do trabalho apontam para a necessidade de iniciativas tanto institucionais quanto pessoais quanto à formação continuada dos docentes que atuam no Ensino Superior.
\end{abstract}

PALAVRAS-CHAVE: Formação continuada. Interdisciplinaridade. Docência Universitária.

\begin{abstract}
The article presents the results of a study aimed to analyze the teaching perspective on interdisciplinary contribution in the teaching practice and the construction of knowledge. It was examined what teachers think, study participants on interdisciplinarity as a sponsor of the development and competence both in the education field and in the field of research; identify the conception of teachers on the scientific knowledge approach, the context of the ideas studied with the reality of the students and the interaction between teacher and student, theory and action. The study was based on contemporary authors, among them: Anastasiou (2006) Fazenda (2001; 2011), Masetto (2008), Piimenta (2000; 2008), Severino (2008) and Veiga (2006) to discuss the university teaching. They interviewed ten (10) teachers of biology courses, Chemistry and Pedagogy of Higher Education Institution of Southwest Bahia. It was found that teachers of different areas of knowledge perceive interdisciplinarity as an approach that provides a closer teaching the complexity of social facts experienced by students, and promotes dialogicity among peers and the interaction between the areas of knowledge. However, research shows that despite the teachers recognize these aspects, interdisciplinarity is little thought and exercised in the studied institution. The results point to the need for both institutional and personal initiatives on the ongoing training of teachers who work in higher education.
\end{abstract}

KEYWORDS: Continuing education. Interdisciplinarity. University Teaching.

\section{RESUMEN}

El artículo presenta los resultados de una investigación con el objetivo de estudiar la perspectiva docente sobre la contribución de la interdisciplinariedad en la práctica docente y la construcción del conocimiento. Procurouse averiguar sobre la interdisciplinariedad como fomentar el desarrollo y la competencia en el campo de la 
investigación; Identificar una concepción de los conocimientos sobre la metodología del conocimiento científico, una contextualización entre las ideas estudiadas con una realidad de los discentes y la interacción entre educador y educando, teoria y acción. Anastasiou (2006), Fazenda (2001; 2011), Masetto (2008), Pimenta (2000; 2008), Severino (2008) y Veiga (2006), que discute una docencia Universitaria Se entrevistó 10 (dez) profesores de los cursos de Biología, Química y Pedagogía de una Institución de Ensino Superior del Sudoeste de Bahía. Constatou-se que los docentes de las diversas áreas del conocimiento perciben una interdisciplinariedad como una forma de abordar el tema de la complejidad de los temas sociales vivenciados por los alumnos, y que promover una diálogo entre los pares. Contudo, una investigación evidencia que, apesar de los docentes reconoce los procesos, una interdisciplinaridad es poco pensada y ejercida en la institución estudiada. Os resultados do trabalho apontam para una necesidad de actuar tanto institucionalmente quanto para formar continuamente dos docentes que actuam no Ensino Superior.

PALABRAS-CLAVE: Educación continua. Interdisciplinariedad. La enseñanza universitaria.

\section{INTRODUÇÃO}

A temática da docência universitária vem abrangendo um grande número de discussões e publicações acadêmicas a fim de discutir a identidade docente, a formação continuada, a Pedagogia Universitária, com estudos na área da Didática para analisar como a prática do professor universitário pode ser ampliada. Ao mesmo tempo, o debate sobre a docência universitária oportuniza estudos nas dimensões do campo pedagógico, referente ao debruçar-se sobre o ensino e a pesquisa, que esta prática esteja interconexa com sua área específica (formação) e sua prática de ensino (docência).

Desse modo, a incorporação da temática docência no ensino superior vem adentrando grupos de trabalho de pesquisa como o GT11 sobre Política da Educação Superior da Associação Nacional de Pós-Graduação e Pesquisa em Educação - ANPED, como em eventos educacionais que ratificam sua relevância e estimulam a participação no debate sobre a temática. A docência universitária é a base da identidade do profissional da educação superior, ao se estudar à docência é necessário levar em consideração o contexto histórico do ensino superior, a melhoria do ensino, as condições de trabalho e de se fazer pesquisa, a temática não deve ser vista somente no sentido da melhoria da formação docente, mas na melhoria da Educação Superior nos aspectos do ensino, da pesquisa e da extensão.

A pesquisa foi desenvolvida com docentes de uma Instituição de Ensino Superior, do Sudoeste da Bahia, analisou-se como a interdisciplinaridade contribui para o desenvolvimento na docência universitária. E objetivou-se analisar a perspectiva docente sobre a contribuição da interdisciplinaridade na prática e na construção do conhecimento. E, especificamente, buscou-se averiguar o que pensam os docentes, participantes do estudo, sobre a interdisciplinaridade como fomentadora do desenvolvimento e competência docente tanto no campo do ensino quanto no campo da pesquisa. Assim como, identificar a concepção dos docentes sobre a abordagem do conhecimento científico, a contextualização entre as ideias 
estudadas com a realidade dos discentes, a interação entre educador e educando e da teoria com a ação. Os resultados do trabalho apontam para a necessidade de iniciativas tanto institucionais quanto pessoais quanto à formação continuada dos docentes que atuam no Ensino Superior.

\section{REFERENCIAL TEÓRICO}

\section{Docência universitária: desafios e perspectivas}

A docência universitária apresenta seus saberes e construções próprias da caminhada de sua formação, as condições de trabalho são diferenciadas pela jornada de cada profíssional desde o vínculo que se firma com a instituição, seja de professor substituto a adjunto. Entretanto, quando ocorre o ingresso na instituição as condições para melhorar seu desempenho enquanto docente são incipientes ou inexistentes em determinadas IES, como podemos perceber pela abordagem de Pimenta (2008, p. 119):

Nem sequer existe uma organização institucional ou espaço para elucidar dúvidas ou repensar com alguma supervisão as ações efetivadas em sala de aula. Nesse contexto, ensinar restringe-se ao tempo de sala de aula, e, por sua vez, as responsabilidades institucionais com o docente limitam-se às da contratação trabalhista.

Além da responsabilidade premissa que é o ensino, o docente tem sua carga horária dividida em outros encargos da universidade, que variam de vínculo integral, parcial e horista. De forma abrangente, além do ensino, ele precisa ter disponibilidade para orientações, funções administrativas dentro da instituição, pesquisa e produção da mesma, projetos de extensão/pesquisa, planejamento e dentre outras responsabilidades como docente. Todos esses aspectos envolvem a identidade desse profissional e sua formação, isto acarreta em um trabalho individualizado e solitário da qual a instituição acaba traduzindo a desvalorização do professor no ensino superior. Diferente desse panorama, existem IES que definem como prioridade "em seus projetos institucionais a profissionalização continuada do docente, investindo e custeando também a hora do estudo, da reflexão e da organização dos processos decisórios relativos aos seus cursos" (PIMENTA, 2008, p. 127).

É preciso pensar nas necessidades dos docentes frente à universidade, essa com relação a organização estrutural física e do currículo, perpassando o conceito de formação que está sendo gerado pela instituição, a percepção do docente com relação a sua formação, se a percebe como processo contínuo e se a partir dessa formação para atuar na docência 
compreende a relação entre o conhecimento específico e pedagógico. São apontamentos que constituem e fazem parte da docência.

Com relação a preparação e aperfeiçoamento da docência universitária, a LDB Lei n. ${ }^{\circ}$ 9.394/96, preconiza no “Art. 66 que a preparação para o exercício do magistério superior farse-á em nível de pós-graduação, prioritariamente em programas de mestrado e doutorado". Diante do que a LDB constitui, esta preparação ou aperfeiçoamento para lecionar no ensino superior depende de cada instituição e do engajamento pessoal de cada docente, para o que problematiza à docência universitária.

De acordo com Anastasiou (2006), esta formação é oferecida de forma insuficiente para o que sistematiza à docência, em nível de pós-graduação esta formação se sucumbe a uma disciplina que é ofertada obrigatoriamente ou específico aos bolsistas do programa da instituição. Essa disciplina como é chamada de Metodologia de Ensino Superior ou Didática de Ensino Superior com uma carga horária de 60 horas a depender da instituição e do nível do stricto sensu, não problematiza e sistematiza os saberes necessários do campo da docência sem fazer "associação entre a teoria e prática desta área, de complexidade indiscutível" (ANASTASIOU, 2006, p. 147).

Para Isaia (2006, p. 65) esta formação/preparação:

[...] não é contemplado nos currículos dos diversos cursos de graduação e, na pós-graduação lato ou estrito sensu, apenas está presente na forma de disciplinas esparsas, quando ocorrem, ou em iniciativas mais atuais de contemplar a docência orientada como preparação inicial para o nível superior. Contudo, tais iniciativas não garantem a intenção de preparar efetivamente os docentes a uma das destinações básicas das instituições superiores, que é a formação de futuros profissionais.

É notório que algumas instituições de ensino superior têm organizado ofertas de aperfeiçoamento e formação continuada para os docentes, que de acordo a Anastasiou (2006) pauta-se em semanas pedagógicas com professores da área da pedagogia universitária que fomentam debates e discussões sobre a área da docência.

Os docentes que compõem e ingressam na docência da educação superior são profissionais, como advogados, médicos, químicos, engenheiros, matemáticos que ingressam nessa profissão como Pimenta et al (2008, p. 104) define: "uma decorrência natural dessas suas atividades e por razões e interesses variados" como complemento salarial ou emprego temporário que em determinadas vezes não problematizam o significado de ser professor no ensino superior. A IES já presume que estes profissionais sejam professores, não assumindo a 
responsabilidade/obrigatoriedade de prepará-los professores. A responsabilidade de se problematizar essa questão não advém só ao professor, mas tanto IES quanto o docente ter a percepção da relevância da profissão docente.

É no programa de mestrado que os bolsistas têm a compreensão inicial (mínima) da docência na educação superior, através de estágios ou disciplinas cursadas no mestrado ou doutorado que dá a primeira visão sobre a sala de aula, sobre os alunos, o papel docente, sobre o ensinar, as metodologias, organização do plano de curso/aula, planejamento, do processo de avaliação dentre outros aspectos que não são pensados e problematizados ao ser/perceber-se professor universitário.

A seguir será abordado e problematizado os desafios na prática de ensino na universidade a partir da análise da interdisciplinaridade, bem como o conceito de interdisciplinaridade e de como ela pode contribuir para que a prática de ensino do docente seja pensada e exercida de forma que incite os discentes à construção do pensamento crítico frente ao conhecimento/mundo e ciência/existência de maneira reflexiva acerca de sua profissionalização no ensino superior.

\section{Interdisciplinaridade: desafios na prática de ensino na universidade}

A interdisciplinaridade não tem uma definição estabelecida, única ou estável, trata-se de um neologismo cujo significado nem sempre é o mesmo e nem compreendido da mesma forma. Sua significação, na maioria das vezes, se dá em um contexto disciplinar, portanto, a interdisciplinaridade pressupõe a interação ou diálogo de pelo menos duas disciplinas e que esta ação seja recíproca. Neste sentido, "a perspectiva interdisciplinar não é, portanto, contrária à perspectiva disciplinar; ao contrário, não pode existir sem ela e, mais ainda, alimenta-se dela" (LEONIR, 2008, p. 46).

Os debates sobre interdisciplinaridade chegaram ao Brasil através dos estudos da obra de Georges Gusdorf. No campo da epistemologia, Hilton Japiassú foi influenciado por Gusdorf e no campo da educação, Ivani Fazenda. Foi através de Fazenda que surgiram grandes obras e um estudo relevante sobre a temática. A interdisciplinaridade é discutida tanto no campo epistemológico quanto pedagógico, seu sentido segue a linha de ousadia e busca de conhecimento, podendo ser entendida também como interação e integração entre as mais variadas áreas do conhecimento e dos profissionais que as exercem. No sentido da epistemologia, ela segue a linha de raciocínio entre o conhecimento e aspectos de produção, mediação entre o sujeito e a realidade. 
A interdisciplinaridade é abrangente em se tratar de propor um ensino menos fragmentário do conhecimento e vai além com os pressupostos de trazer para o campo educacional o peso significativo das relações cotidianas para a aprendizagem de um conhecimento tido como totalidade. O saber não pode perder sua complexidade, podendo exercer-se interdisciplinarmente. Na conjuntura do saber, a interdisciplinaridade é exigência de o engajamento pessoal, dessa forma o "saber é a face subjetiva da coletividade política dos sujeitos. Em todas as esferas de sua prática, os homens atuam como sujeitos coletivos" (LEONIR, 2008, p. 45).

Fazenda (2001) enfatiza que o conceito de interdisciplinaridade é polissêmico, dependendo de possibilidades a serem apropriadas ao analisar por diferentes perspectivas o mesmo assunto. É necessário saber interpretar os elementos do cotidiano, compreender a linguagem de diferentes modalidades - posicionamento reflexivo. Para viver e exercer a interdisciplinaridade é necessário ter uma formação acoplada em práticas de situações reais e contextualizadas. Neste sentido, "conhecer o lugar de onde se fala é condição fundamental para quem necessita investigar como proceder ou como desenvolver uma atitude interdisciplinar na prática cotidiana" (FAZENDA, 2001, p. 23).

$\mathrm{O}$ avanço de inovações científicas e tecnológicas vem crescido cada vez mais nas instituições de ensino superior (IES), a universidade avança continuamente no desenvolvimento da ciência, e se adapta a mudanças, fazendo com que os discentes as percebam na graduação através do ensino/pesquisa. Através do que a LDB Lei no 9.394/96 atribui ao desenvolvimento dos graduandos do Ensino Superior sanciona no Art. 43, que se deve:

III. incentivar o trabalho de pesquisa e investigação científica, visando o desenvolvimento da ciência e da tecnologia e da criação e difusão da cultura, e, desse modo, desenvolver o entendimento do homem e do meio em que vive; VI. Estimular o conhecimento dos problemas do mundo presente, em particular os nacionais e regionais, prestar serviços especializados à comunidade e estabelecer com esta uma relação de reciprocidade.

A LDB deixa explícito um caráter interdisciplinar ao Ensino Superior, fazendo junção da pesquisa científica está conexa com a realidade dos sujeitos inseridos nas IES, ou seja, fazer perceberem o contexto das disciplinas e pesquisas científicas com a realidade de sua comunidade, estado ou país. Para isso acontecer de fato na prática do docente universitário, é imprescindível analisar os desafios na prática educativa que estão implícitos na construção de um trabalho articulado e cooperativo. Desta forma se delimitam: 
Os desafios tanto docentes quanto institucionais evidenciam diferentes dimensões. Entre elas, destaca-se a necessidade de os professores, além de considerarem seus domínios específicos, investirem na dimensão pedagógica da docência. Esta envolve atividades e valores traduzidos em sensibilidade ante o aluno; valorização dos saberes da experiência; ênfase nas relações interpessoais; aprendizagem compartilhada (professores e alunos); integração teoria/prática; e, também, o ensinar a partir do respeito à aprendizagem do aluno (ISAIA, 2006, p. 76).

Os desafios citados são de fundamental importância para a formação pessoal do estudante e também da formação profissional do docente, sendo necessários que as instituições de ensino superior levem em consideração as necessidades e expectativas dos docentes frente ao pleno desenvolvimento profissional, ao apreciar as exigências do exercício da docência universitária acerca das políticas e diretrizes para a formação continuada e em exercício.

Outro desafio que impede para que essa prática interdisciplinar aconteça, é com relação à superação do exacerbado uso da razão lógica que tem a ver com a teoria do terceiro excluído, onde não assumimos ou concebemos uma terceira possibilidade ou resposta diferente de A e B. A sociedade, em suas variadas instâncias educacionais, tem demonstrado o ensino cada vez mais fragmentário, nos especializamos cada vez mais, para compreendermos uma única parcela do todo. Não que a interdisciplinaridade irá fazermo-nos de máquina depositária de conhecimento, mas aprender a dialogar com os parceiros que falam da mesma área de conhecimento, em prol de um projeto que objetive um conhecimento novo (ÁVILA, 2011).

\section{O ensino - pesquisa interdisciplinar na docência universitária}

Debruçar sobre a prática interdisciplinar é pensar primeiramente através do entendimento da existência do ser humano que poderá compreender o sentindo da prática, pois, como definiu Severino (2008), a essência do existir é a prática. É na prática e pela prática que os ideais humanos acontecem e que a história se faz. Ampliando a prática o docente estará a refletir sobre sua ação e as decisões concretas que se toma no cotidiano, construindo saber a partir da ação.

Para Fazenda (2001), a prática interdisciplinar baseia-se em trocas intersubjetivas, que é justamente a postura do profissional que está aberto a intervenções junto aos professores, para a construção de uma didática transformadora, interdisciplinar, proporcionando trocas, 
estimulando autoconhecimento sobre a prática de cada um e ampliando leituras de práticas não desvendadas do cotidiano. É ter revelado em seu trabalho um sentimento de parceria com outros educadores que lutam por uma educação melhor, parceria com os discentes na construção do conhecimento. Percebe-se através dessas atitudes interdisciplinares que o caminho constante para a mesma é o pensar, o questionar e o construir. Desse modo, a autora faz refletir:

[...] os projetos interdisciplinares, em nível de universidade, têm procurado na busca de superação da dicotomia ensino/pesquisa transformar as salas de aula dos cursos de graduação em locais de pesquisa, e não esperar que a pesquisa fique reservada apenas à pósgraduação (FAZENDA, 2001, p. 88).

É próprio da interdisciplinaridade, aprender a pesquisar, fazendo pesquisa e de princípio universitário a pesquisa coletiva, em que seria necessária uma pesquisa nuclear que acoplasse todos os diferentes pesquisadores e que, cada um pudesse revelar sua própria potencialidade e competência. A interação entre docente e discente é de suma relevância, o docente possibilita ao discente ampliar seu universo de leitura e conhecimento, lhe permite criar um olhar crítico. A percepção e conhecimento dos dois ampliam a educação e a forma de transformação da mesma.

Assim, o pesquisador do presente está preocupado com a importância do seu trabalho, revelando suas limitações na forma dinâmica de estar sempre aberto ao novo, dividindo-se em dois comportamentos: individual e em parceria. O primeiro refere-se aquele que se debruça sobre a realidade e extrai dela conhecimentos essencialmente originais que carregue sua marca, no qual ele analisa suas características e singularidades. Por mais atualizado que seja a produção teórica sobre a questão, seu olhar e reflexão é limitado e parcial. O segundo se refere da necessidade do diálogo com seus parceiros de pesquisa de mesmo objeto, que trocará conhecimento sobre suas angústias e inquietações e encontrará um espaço de construção consensual e operacional de ser atualizado a qualquer momento. Assim, "cria-se no grupo uma atmosfera emocional-racional em que circulam professores e alunos, todos pesquisadores e, sobretudo, pessoas, pares que, entre si, legitimam e avançam coletivamente na produção/divulgação do conhecimento" (KENSKI, 2008, p.137).

O trabalho dos professores universitários depende muito do que almeja a instituição a que pertencem, pode-se perceber que:

As incertezas que afligem a universidade não são apenas institucionais. Os próprios docentes universitários, como não poderia 
deixar de ser, encontram-se envolvidos nessa crise de identidade. Invadem-nos incertezas a respeito do que somos, do que e como devemos ensinar, de quais temas devemos privilegiar em nossas pesquisas, a serviço de quem estamos ou deveríamos estar (BORBA et al, 2006, p. 205).

As incertezas que a autora cita comprometem o tipo de ensino que será pensado pelos professores, pois, na contemporaneidade, com tamanhas teorias educacionais e problemas sociais que devem ser abordados na instância universitária, teme a escolha do que seja necessário para a formação dos cidadãos.

Segundo Kenski (2008), o grupo de estudos e pesquisa possibilita a melhor formação de professores-pesquisadores que, em seguida, em outras instituições educacionais, poderão formar seus próprios grupos de estudo, a compreender que a pesquisa é a única forma possível de aprendizagem, ou seja, uma interliga com a outra (ensino-pesquisa).

A seguir, será descrito o percurso metodológico para a condução da pesquisa, bem como sua análise, ressaltando a escolha do tema, os sujeitos pesquisados, as áreas de saber escolhidas, o instrumento que serviu a pesquisa acerca da percepção da interdisciplinaridade no ensino superior.

\section{MATERIAIS E MÉTODOS}

Esta pesquisa centra-se na análise da compreensão dos professores de uma Instituição de Ensino Superior no Sudoeste da Bahia, na cidade de Itapetinga/BA - em específico dos cursos de Biologia, Química e Pedagogia referente a interdisciplinaridade na docência universitária. Compreender sua instância enquanto fomentadora do ensino, pesquisa e extensão e das mais variadas incumbências, buscando saber como a interdisciplinaridade na prática do docente contribui para o desenvolvimento na aprendizagem dos discentes.

Esta pesquisa é de abordagem qualitativa, pois aprecia uma relação entre o mundo real e o sujeito, que é tido como indissociável, pois não pode ser traduzido em números. Diferente da pesquisa quantitativa, "os métodos qualitativos consideram a comunicação do pesquisador em campo como parte explícita da produção de conhecimento, em vez de simplesmente encará-la como uma variável a interferir no processo" (FLICK, 2009, p. 25). Tornando-se parte do processo de pesquisa a subjetividade dos sujeitos pesquisados, assim como do pesquisador. A pesquisa apresenta-se descritiva, tendo como foco principal o processo e seu significado: "O ambiente natural é a fonte direta para coleta de dados e o pesquisador é o instrumento-chave. Tal pesquisa é descritiva. Os pesquisadores tendem a analisar seus dados indutivamente" (PRODANOV et al, 2013, p. 70). 
Os dados foram coletados no segundo semestre de 2015, em uma instituição de Ensino Superior pública multicampi. No campus em que foi realizada a pesquisa a IES oferece 9 cursos nas áreas de ciências agrárias, ciências exatas e da terra, ciências humanas, ciências da saúde e engenharias.

Foram escolhidos 10 docentes para fazer parte deste estudo, sendo dos cursos de Química, Biologia e Pedagogia. Com relação a amostragem, definindo-se que "o conceito de amostra é ser uma porção ou parcela, convenientemente selecionada do universo (população); é um subconjunto do universo" (MARCONI et al, 2003, p. 223). O critério para as escolhas das áreas de conhecimento foi de maneira distinta, abrangendo diferentes áreas de estudo (Ciências Exatas e da Terra, Ciências da Saúde e Ciências Humanas).

Os participantes do estudo foram entrevistados, com um roteiro de entrevista composto por 3 perguntas subjetivas por qual todos os docentes se dispuseram a responder. $\mathrm{O}$ método para analisar as entrevistas foi indutivo e descritivo, que não se delimita só a descrever os dados, mas "acrescentar algo ao questionamento existente sobre o assunto. Para tanto, ele terá que fazer um esforço de abstração, ultrapassando os dados, tentando possíveis explicações, configurações e fluxos de causa e efeito" (GIL, 2002, p. 176). A categorização foi dada a partir do que foi exposto de aspectos relevantes da interdisciplinaridade na docência universitária, e dos objetivos traçados na pesquisa.

\section{ANÁLISE DOS DADOS E RESULTADOS}

\section{Percepção dos docentes sobre a interdisciplinaridade na docência universitária}

No intuito de apreender o que pensam os docentes sobre a interdisciplinaridade e poder analisar a perspectiva docente sobre a contribuição da interdisciplinaridade na prática docente e na construção do conhecimento, foi apresentado o seguinte questionamento aos participantes da pesquisa: “Qual sua concepção sobre interdisciplinaridade?”. Os depoimentos revelaram não só a concepção dos docentes sobre a temática abordada, mas deixaram transparecer aspectos de sua prática docente:

Eu acho que a interdisciplinaridade você tem que saber usar, por exemplo, dentro da sua disciplina os conceitos cotidianos a ação em relação a todo o universo que circunda, por exemplo, nas aulas de conservação a gente fala não só de conservação, mas de outras questões politicas, ambientais, sociais que dizem respeito a conservação que não é simplesmente uma ciência individualizada ela está agregada a várias outras ciências, a várias outras questões. Tem uma validade muito grande no sentido de formar individuos críticos, 
maduros para debater os diversos temas associados a uma determinada linha de atuação ou de pensamento. [DOCENTE ABIOLOGIA]

A fala indica que o docente compreende que a interdisciplinaridade é mais que a interação entre duas ou mais disciplinas, possibilita uma visão do planejamento da prática docente e a dialogicidade com outras áreas do saber (ciências), entre os educadores, os discentes e a criticidade que é necessária para o futuro profissional que está sendo formado desenvolva. Nessa perspectiva, far-se-á reflexão do pensamento de Fazenda (2001) a respeito da interdisciplinaridade possibilitar um olhar crítico, de pesquisador, que perceba os problemas/questões sociais que fazem parte da universidade, pois ela é um ambiente social e que perpassa pelas mesmas dificuldades que o mundo social vive. "A lógica que a Interdisciplinaridade imprime é a da invenção, da descoberta, da pesquisa, da produção científica, porém, gestada em um ato de vontade, em um desejo planejado e construído em liberdade" (FAZENDA, 2011, p. 29). Assim, um outro docente apresenta em sua fala que a:

Interdisciplinaridade é a possibilidade de diálogo entre várias áreas do conhecimento. Eu entendo que interdisciplinaridade é essa possibilidade de você Intertextualizar o conhecimento com o todo, tanto no sentido vertical quanto no sentido horizontal, quando eu falo no sentido vertical da possiblidade de você pegar o seu conteúdo e dialogar com várias disciplinas, de uma maneira mais horizontal dialogar as outras disciplinas com o seu conteúdo, ou seja, a possiblidade de intercomunicação entre as disciplinas, não somente entre as disciplinas, mas nas práticas, entre as áreas de conhecimento. [DOCENTA A-PEDAGOGIA]

A concepção de interdisciplinaridade revelada pelos docentes condiz com a perspectiva dos autores descritos neste estudo, quando demonstram em seus relatos elementos vivos da prática docente de intercontextualização da teoria/prática, da necessidade de aproximar os conteúdos não só com as demais disciplinas, mas com as teorias que estão efervescendo a sala de aula, com os discentes e nas aulas práticas. Assim como Fazenda (2001) e Severino (2008) expuseram em seus estudos que a prática é a essência da vida e poder confrontar/analisar o que está praticando com os teóricos da área específica e das demais áreas do saber, percebendo que para se compreender algo é imprescindível analisarmos o todo a partir das contribuições e percepções de cada área.

O entendimento dos professores sobre a temática, está de acordo que a "Interdisciplinaridade não é uma panaceia que garantirá um ensino adequado, ou um saber 
unificado, mas um ponto de vista que permite uma reflexão aprofundada, crítica e salutar sobre o funcionamento do mesmo" (FAZENDA, 2011, p. 74).

Os relatos dos docentes revelam a fluidez em definir o termo, que é algo que se identifica na revisão de literatura, onde os autores afirmam que ainda não se tem um conceito definido do que seja a interdisciplinaridade, pois ela não é uma ciência e muito menos uma metodologia, como explicita Fazenda (2011), é bem mais do que um ponto de vista que analisa e permite uma reflexão aprofundada do funcionamento do ensino. Pode-se constatar na fala do docente a seguir:

Interdisciplinaridade, na minha concepção, é você trabalhar um determinado tema dentro da sua área, de forma não isolada. É você tentar fazer pontes, ver onde o aluno vai poder aplicar aquilo ali, em quais áreas do conhecimento e fazendo dessa maneira, você acaba fugindo um pouco da sua realidade [...]. Pegando exemplos ligados à realidade do aluno, fica fácil para ele entender, porque a matéria não é isolada ela tem que ser aplicada em outras áreas do conhecimento. Então, o professor tem por obrigação tentar mostrar para o aluno essa interdisciplinaridade, que a matéria não está isolada, ela não é uma peça separada ela tem que estar unida a todo um outro contexto. [DOCENTE A-QUÍMICA]

Os depoimentos dos docentes corroboram que os entrevistados conhecem e buscam exercer a interdisciplinaridade, mas deixam transparecer em algumas falas que ela se obstina só a determinadas interações entre as disciplinas. Não percebendo sua ampla visão de melhoria da formação humana, o que sugere os autores que se dedicam ao estudo da interdisciplinaridade apresentados neste trabalho.

A pesquisa revela que o entendimento de alguns entrevistados abrangesse muito a interdisciplinaridade impulsionar apenas a trabalhar um determinado conceito de outras áreas dentro de sua disciplina, mas como Fazenda (2011, p. 54) elucida em seu trabalho "essa interação pode ir da simples comunicação de ideias à integração mútua dos conceitos, da terminologia, da metodologia, dos procedimentos, dos dados e da organização referentes ao ensino e à pesquisa".

Com relação a interação ente as disciplinas, o entendimento de alguns entrevistados abrangesse muito a interdisciplinaridade impulsionar apenas a trabalhar um determinado conceito de outras áreas dentro de sua disciplina, mas como Fazenda (2011, p. 54) elucida em seu trabalho "essa interação pode ir da simples comunicação de ideias à integração mútua dos conceitos diretores da epistemologia, da terminologia, da metodologia, dos procedimentos, dos dados e da organização referentes ao ensino e à pesquisa". 
Ao serem questionados sobre a concepção de interdisciplinaridade, os docentes revelaram a necessidade de refletirem como sujeitos interdisciplinares. É dessa questão que o próximo item se encarregará: os sujeitos da pesquisa se considerarem ou não interdisciplinares em sua prática de ensino e pesquisa?

\section{Percepção dos professores sobre a percepção da interdisciplinaridade em sua prática e incentivo à pesquisa}

Buscou-se saber como os docentes percebem a interdisciplinaridade na sua prática docente, se a compreendem como fomentadora do desenvolvimento e competência docente, tanto no ensino quanto na pesquisa. Para tanto, foi apresentada o seguinte questionamento: "como a interdisciplinaridade se manifesta em sua prática docente e no incentivo a pesquisa?

"As respostas dos entrevistados revelam desde a articulação da interdisciplinaridade como prática viva, discorrendo sobre o desenvolvimento das disciplinas que ministram e como é a articulação da interdisciplinaridade no incentivo a pesquisa:

... eu busquei conversar mais com colegas que tem uma proximidade com a área da infância, conversar no sentido de pensar, por exemplo: quando eu começo com meu conteúdo, onde termino, onde pauso e se há sombreamento ou não das nossas disciplinas, sombreamento de conteúdo. [...] A provocação de uma organização de um projeto de trabalho, ai eu acho que a interdisciplinaridade ela surge bem bacana é que ela vai ser o eixo que vai articular uma forma de trabalho do professor com a turma que vai potencializar, que vai impulsionar, vai provocar nos alunos essa questão da pesquisa. [DOCENTE BPEDAGOGIA]

[...] Eu sou do grupo das ciências exatas e tecnológicas e minha área de atuação é cálculo diferencial. Então o que eu tento fazer é estabelecer uma ponte entre os conceitos da disciplina de cálculo diferencial e os fenômenos que vemos na natureza. A gente sempre está modelando algum fenômeno da natureza, algo do dia a dia e trazendo para a disciplina. Em relação ao incentivo à pesquisa é importante porque na maioria dos projetos de pesquisa você tem que partir de um fenômeno e tenta através daquele fenômeno modelar aquela ciência e trazer para a matemática e através da matemática, depois que estabeleceu um modelo e ai provar que você pode utilizar de várias formas dentro da sua disciplina. [DOCENTE $A$ QUÍMICA]

$\mathrm{Na}$ fala dos docentes tanto de Pedagogia quanto de Química, deixa evidente que a interdisciplinaridade se manifesta na interação entre as disciplinas, proporcionando uma dialogicidade mais abrangente, sem dissociar a teoria da prática. Que está de acordo com o 
pensamento de Fazenda (2011, p. 54) fazendo perceber que a interação entre as disciplinas vai além da "simples comunicação de ideias à integração mútua dos conceitos diretores da epistemologia, da terminologia, da metodologia, dos procedimentos, dos dados e da organização referentes ao ensino e à pesquisa". Os depoimentos nos permitem inferir que os docentes consideram que organizam a sua prática e incentivam aos alunos a pesquisarem numa perspectiva interdisciplinar, pois é papel do professor-pesquisador que está engajado em um movimento dialético, determinar a reflexão sobre sua própria ação, tendo como princípio analisar suas próprias produções, procurando rever novas problemáticas a partir dessas produções.

Alguns docentes pesquisados sentem a dificuldade de fazerem um trabalho interdisciplinar, justamente pela própria formação que tiveram, outros atribuem essa dificuldade pela matriz curricular dos cursos de graduação. Isto faz refletir de como os professores percebem à docência e de como se percebem sujeitos interdisciplinares, porque já não tiveram uma formação tendo como problemática o ensino, devido a terem como base principal em seu magistério superior a pesquisa. O fazer-se docente vai muito além das experiências que trazem consigo do que seja o papel do professor, "essas experiências que muitas vezes guiaram sua opção profisssional, vão guiar suas escolhas pedagógicas e até mesmo seu relacionamento com os alunos. Experiências que lhes possibilitam dizer quais eram bons professores" (RIVAS et al, 2007, p. 4).

Os docentes dessa instituição pesquisa desenvolvem o ensino juntamente com a pesquisa, estabelecendo parcerias entre os docentes que conversam na mesma área e disciplinas afins, promovendo uma metodologia de ensino que esteja mais interligada com a realidade social não só dos alunos, mas da área de atuação desses futuros profissionais, a exemplo do depoimento a seguir:

\section{[...] quando a gente está discutindo a questão ambiental a gente não tem como pensar nos nossos problemas ambientais sem pensar nas questões sociais, sem pensar em economia, em filosofia, em psicologia, por exemplo, quando a gente fala em consumo exacerbado, o porquê de estarmos consumindo dessa forma, o porquê de estarmos vivenciando esse momento conflituoso nas nossas relações... [DOCENTE D - BIOLOGIA]}

Outro aspecto que pode ser destacado é o fato do caráter interdisciplinar impulsionar maior diálogo e parceria entre as áreas do saber, como é afirmado na fala do professore de Biologia, que segundo Fazenda (2001, p.85), a parceria entre os docentes no 
ensino/trabalho/pesquisa, consistiria "por assim dizer, a possibilidade de consolidação da intersubjetividade - a possibilidade de que um pensar venha a se complementar no outro".

Parceria que se amplia entre os educadores que almejam uma educação de qualidade; entre os discentes, possibilitando maior interesse ao conhecimento e, proporcionado, por fim, uma aprendizagem mais significativa. A autora acrescenta que "o fato é que nem sempre nos damos conta dessas parcerias. O sentido de um trabalho interdisciplinar estaria na compreensão e na intencionalidade da efetivação de novas e melhores parcerias" (FAZENDA, 2001, p. 85).

Os depoimentos revelam a percepção dos docentes de que a interdisciplinaridade se manifesta na prática e no incentivo a pesquisa de forma contextualizada com os problemas sociais e da realidade dos discentes, para perceberem a funcionalidade do que estão estudando/pesquisando, fazendo da sala de aula um ambiente de pesquisa. Empreendendo esforços “[...] na busca de superação da dicotomia ensino/pesquisa transformar as salas de aula dos cursos de graduação em locais de pesquisa, e não esperar que a pesquisa fique reservada apenas à pós-graduação” (FAZENDA, 2001, p. 88).

Os professores entrevistados acreditam que desenvolvem um ensino articulado com a pesquisa, estabelecendo parcerias com colegas que atuam na mesma área e, ou disciplinas afins, promovendo uma metodologia de ensino mais articulada com a realidade social não só dos alunos, mas da área de atuação desses futuros profissionais.

\section{Concepção dos docentes sobre a contextualização dos conteúdos e a interação entre educador-educando e teoria-ação}

A concepção dos docentes sobre a abordagem do conhecimento científico, a contextualização dos conteúdos estudados e a interação entre educador e educando, teoria e ação foi obtida através das respostas apresentadas ao questionamento: "Como você aborda os conteúdos da disciplina que você ministra? Você contextualiza esses conteúdos com a realidade de seus discentes?" Os depoimentos dos professores sugerem a relevância de fazer uma aula que seja significativa para o discente e que este possa contextualizar com suas vivências, tornando o aprendizado mais significativo e fomentado novos questionamento e pesquisa.

Sem dúvida, isso é fundamental. É o que eu falo até nos nossos livros de ecologia, a gente tem tantos exemplos da Europa, da América do Norte, a gente não tem um livro de ecologia voltado para os 
ecossistemas brasileiros. Então a gente tem sempre que trazer pra cá a realidade da Bahia, a realidade de Itapetinga. [DOCENTE CBIOLOGIA]

Com certeza! Você contextualiza os conteúdos de suas disciplinas ou de outras disciplinas com as próprias experiências, com as vivências que os alunos têm. Eu acho que parte um pouco dai ..., dessa questão de você não fechar o conhecimento restrito à sua área de saber, mas ter essa possibilidade de dialogar com outros ramos do conhecimento. Agora isso requer que o professor tenha uma trajetória profissional também trazendo isso, porque às vezes você tem uma possiblidade de trajetória profissional muito fechada, sobretudo quem trabalha nas "ciências duras", ainda que não seja uma coisa que somente acontece lá. Mas, geralmente, a área do conhecimento fica estanque, por exemplo: trabalho na química com uma disciplina especifica química analítica. Minha disciplina não permite o diálogo com outras disciplinas e me fecho nela. A interdisciplinaridade propõe exatamente o contrário. [DOCENTE C - PEDAGOGIA]

Os professores pesquisados afirmaram contextualizar os conteúdos que são ministrados em suas disciplinas com a realidade/vivências dos estudantes de forma regional e nacional, falando de forma concisa como abordam os conteúdos das suas disciplinas. Merece destaque o relato do Docente B, do curso de Biologia, que afirma que o material de estudo da disciplina que ministra é distante da realidade da região e do país revelando sua preocupação com a necessária contextualização e a importância de elaborar uma aula a partir da realidade que os discentes conhecem. Os demais relatos revelam que os docentes reconhecem a relevância de problematizar o que está sendo estudado, estabelecendo uma interação e trocas com os alunos no processo de construção do conhecimento a partir das vivências e a da realidade imediata, na ação de conhecer e intervir na instância social.

Vale salientar que ao aproximar a teoria da ação os docentes estão preparando os seus discentes para a pesquisa, para "saber analisar as situações, saber colocar os problemas de uma forma geral e conhecer os limites de seu próprio sistema conceitual" (FAZENDA, 2011, p. 77). Demonstrando que a prática não existe sem a teoria, a ampliação da prática não elimina a criação e ampliação também da teoria é uma etapa integradora da sistematização dos conhecimentos.

A “interação" que os docentes citam entre as disciplinas, as áreas de saber e entre os pares (professores) é imprescindível para que aconteça, de fato, um trabalho interdisciplinar, pois a dialogicidade entre o campo de saber de um e a especificidade do outro trará, para ambos, um trabalho conjunto. Lembrando que essa integração permite uma visão muito mais ampliada da realidade e que, ainda assim, não pode ser considerada como algo definitivo. 
Fazenda (2011) esclarece que a integração é uma ponte e sempre pode ser pensada/reformulada.

A interação seria "no sentido de questionar a própria realidade e suas perspectivas de transformação, ou seja, a integração seria uma etapa anterior à interdisciplinaridade" (FAZENDA, 2011, p. 83), através da iniciação de um estudo seria em seguida informado sobre as possíveis conclusões. Neste sentindo, os professores também expõem que a prática de contextualizar e trazer algo que seja mais próximo dos estudantes faz parte de suas aulas, é uma forma de conexão entre a realidade social e o conhecimento científico, que desta forma os alunos apresentam um resultado mais positivo de suas aprendizagens.

Sim, procuro sempre contextualizar os conteúdos. Porque algo que você procura contextualizar e se propõe trabalhar de forma interdisciplinar, [...] você tem que fomentar o questionamento do aluno. E, principalmente, partir da realidade deles, se não tiver algo que seja palpável para eles em termos de entendimento, não adianta você trabalhar com ideias mirabolantes que ao invés de aproximar, você vai criar uma lacuna muito maior ainda. [DOCENTE BQUÍMICA]

Essas experiências impulsionam novos debates, novas problemáticas a serem pesquisadas. Ao refletir sobre essa dinâmica em sala de aula, Masetto (2008, p. 180-181) descreve a aula como: "como vivência quer dizer aula como vida, como realidade. A aula como espaço que permita, favoreça e estimule a presença, a discussão, o estudo, a pesquisa, o debate...”. É um espaço que se impregna de fatos, de acontecimentos, estudos, análise, discussões teóricas que agitam a universidade, é trazer o contexto da universidade, dos grupos de pesquisa e refletir e agir sobre ele.

Essa postura interdisciplinar favorece não só ao aluno, mas, sobretudo, ao professor que está sempre reinventado e aprimorando sua prática, se aperfeiçoando em seu campo de saber, e procurando não ser o melhor, mas fazer com que o estudante seja formado para ser um cidadão capaz de intervir nos problemas sociais.

\section{CONSIDERAÇÕES FINAIS}

As reflexões apresentadas neste trabalho corroboram a necessidade de compreender e estudar o campo da interdisciplinaridade enquanto atitude e produção do conhecimento, compreendendo-a para além do campo educacional, no sentido epistemológico e metodológico, como uma possibilidade real de fomentar um trabalho integrado que está em constante reflexão em prol do novo, de apropriar e se aprimorar constantemente. 
Os professores participantes da pesquisa se consideram interdisciplinares, mas revelaram que a interdisciplinaridade nem sempre está presente na prática docente no Ensino Superior, por lacunas da própria formação docente, ou por resistências de alguma natureza. $\mathrm{O}$ estabelecimento de relações entre os conteúdos do ensino e problemática das questões sociais que incita a pesquisa, como também a contextualização dos conteúdos foram aspectos apontados com imprescindíveis e presentes em suas aulas.

A abordagem interdisciplinar do ensino exige a tomada de consciência e a disponibilidade e abertura de estar sempre confrontando teorias, ideias, para um conhecimento novo, na busca da superação da dicotomia ensino-pesquisa, problematizando, a partir das vivências dos estudantes, os conteúdos científicos para a compreensão mais ampla e profícua dos conteúdos escolares e da realidade social.

O estudo revelou que interdisciplinaridade na instituição pesquisada é exercida ainda timidamente, por lacunas na formação docente e por desconhecimento das possibilidades da adoção da perspectiva interdisciplinar em aspectos relacionados ao ensino e à pesquisa. Contudo, alguns professores desenvolvem um trabalho significativo e integrado com seus pares.

A necessidade de se repensar e instituir uma política de formação continuada nas instituições de ensino superior é premente, como aperfeiçoamento da pedagogia universitária e dos saberes educacionais para este nível de ensino. Essa formação deve ser pensada em uma modalidade que permita aos professores conhecerem as teorias educacionais e metodológicas, dialogar sobre suas experiências e métodos que contribuam para um ensino mais dinâmico e crítico. Por fim, ressaltamos que iniciativas quanto à formação continuada dos docentes que atuam no Ensino Superior deve ser objeto de esforços, estudos e de busca tanto institucional, quanto pessoal, para os professores universitários.

\section{REFERÊNCIAS}

ANASTASIOU, Léa das Graças Camargo. Docência na Educação Superior. In: RISTOFF, Dilvo; SERVEGNANI, Palmira (Org.). Educação Superior em Debate: Docência na educação superior. 5 ed. Brasília-DF: Inep, 2006.

ÁVILA, Cristiane. Interdisciplinaridade e transdisciplinaridade: desafios no planejamento e prática de ensino na universidade. In: RIBEIRO, Marinalva Lopes; MARTINS, Édiva de Souza; CRUZ, Antônio Roberto Seixas da (Org.). Docência no ensino superior: desafios da prática educativa. Salvador: Edufba, 2011.

BORBA, Amândia Maria de; FERRI, Cássia; HOSTINS, Regina Célia Linbanes. Formação continuada de professores universitários: alguns enfrentamentos necessários. In: RISTOFF, 
Dilvo; SERVEGNANI, Palmira (Org.). Educação Superior em Debate: Docência na educação superior. 5 ed. Brasília-DF: Inep, 2006.

BRASIL. Ministério da Educação. Lei n. 9.394 de 20 de dezembro de 1996. Estabelece as diretrizes e bases da educação nacional. Brasília, 1996.

FAZENDA, Ivani C. Arantes. Interdisciplinaridade: história, teoria e pesquisa. 7. ed. Campinas: Papirus, 2001.

FAZENDA, Ivani C. Arantes. Integração e interdisciplinaridade no ensino brasileiro: Efetividade ou ideologia. 16. ed. São Paulo: Loyola, 2011.

FLICK, Uwe. Introdução à pesquisa qualitativa: Métodos de pesquisa. 3. ed. São Paulo: Artmed, 2009.

GIL, Antônio Carlos. Como elaborar projetos de pesquisa. 4. ed. São Paulo: Atlas, 2002.

GUIMARÃES. Valter Soares. A docência universitária e a constituição da identidade profissional do professor. In: RIBEIRO, Marinalva Lopes; MARTINS, Édiva de Souza; CRUZ, Antônio Roberto Seixas da (Org.). Docência no ensino superior: desafios da prática educativa. Salvador: Edufba, 2011.

ISAIA, Silvia Maria de Aguiar. Desafio à docência superior: pressupostos a considerar. In: RISTOFF, Dilvo; SERVEGNANI, Palmira (Org.). Educação Superior em Debate: Docência na educação superior. 5. ed. Brasília-DF: Inep, 2006.

KESNKI, Vani Moreira. A formação do professor-pesquisador: experiências no grupo de pesquisa "memória, ensino e novas tecnologias (MENT)". In: FAZENDA, Ivani C. Arantes. Didática e interdisciplinaridade. 13. ed. São Paulo: Papirus, 2008.

LEONIR, Yves. Didática e interdisciplinaridade: uma complementaridade necessária e incontornável. In: FAZENDA, Ivani C. Arantes. Didática e interdisciplinaridade. 13. ed. São Paulo: Papirus, 2008.

MASETTO, Marcos T. Aula na universidade. In: FAZENDA, Ivani C. Arantes. Didática e interdisciplinaridade. 13 ed. São Paulo: Papirus, 2008.

MARCONI, Marina de Andrade; LAKATOS, Eva Maria. Fundamentos de Metodologia científica. 5 ed. São Paulo: Atlas, 2003. FAZENDA, Ivani C. Arantes

PIMENTA, Selma Garrido. Formação de professores: saberes da docência e identidade do professor. In: FAZENDA, Ivani C. Arantes. Didática e interdisciplinaridade. 13. ed. São Paulo: Papirus, 2008.

PRADANOV, Cleber Cristiano; FREITAS, Ernani Cesar de. Metodologia do Trabalho Científico: Métodos e Técnicas da Pesquisa e do Trabalho Acadêmico. 2. ed. Nova Hamburgo-Rio Grande do Sul-Brasil: Universidade Feevale, 2013. 
SEVERINO, Antônio Joaquim. O pedagógico e a interdisciplinaridade: o saber como intencionalização da prática. In: FAZENDA, Ivani C. Arantes. Didática e interdisciplinaridade. 13. ed. São Paulo: Papirus, 2008.

VEIGA, Ilma Passos Alencastro. Docência universitária na educação superior. In: RISTOFF, Dilvo; SERVEGNANI, Palmira (Org.). Educação Superior em Debate: Docência na educação superior. 5. ed. Brasília-DF: Inep, 2006. 